\title{
CHARACTERIZATION OF VEHICLE EMISSIONS IN VANCOUVER BC DURING THE 1993 LOWER FRASER VALLEY OXIDANTS STUDY
}

\author{
ALAN W. GERTLER, DAVID N. WITTORFF, ROBERT MCLAREN, $\uparrow$ \\ WAYNE BELZER $\ddagger$ and TOM DANN§
}

\begin{abstract}
*Desert Research Institute, P.O. Box 60220, Reno, NV 89506, U.S.A.; †Department of Chemistry and Centre for Atmospheric Chemistry, York University, 4700 Keele St., North York, Ont., Canada M3J 1P3; †Science Division, Environment Canada, 700-1200 West 73rd Avenue, Vancouver, British Columbia, Canada V6P 6H9; and §Pollution Measurement Division, Environmental Technology Center, Ottawa, Ont., Canada K1A OH3
\end{abstract}

\begin{abstract}
As part of the 1993 Lower Fraser Valley Oxidants Study, measurements of mobile source emission factors were performed in the Cassiar Tunnel on the Trans-Canada Highway to measure the on-road contribution to the ozone-forming precursors ( $\mathrm{NO}_{x}$ and speciated hydrocarbons) along with $\mathrm{CO}$. Observed emission factors were compared to the Canadian versions of the U.S. Environmental Protection Agency's MOBILE models, MOBILE4.1C and MOBILE5C, to assess uncertainty in the predicted mobile source contributions to the Vancouver emissions inventory.

A total of $161-\mathrm{h}$ runs were made. The timing of the individual runs was designed to encompass different traffic volumes, driving conditions, and times of day. A total of 24,513 vehicles traversed the tunnel during the study, with approximately $91 \%$ light-duty vehicles, $4 \%$ heavy-duty spark ignition vehicies, and $5 \%$ heavy-duty diesel vehicles. MOBILE5C overpredicted the observed value of CO by $\sim 2 \%, \mathrm{NMHC}$ by $24 \%$, and $\mathrm{NO}_{x}$ by $13 \%$, while MOBILE4.1C underpredicted the observed values by 36,29 , and $23 \%$ for $\mathrm{CO}$, NMHC, and $\mathrm{NO}_{x}$, respectively. (C) 1997 Elsevier Science Ltd.
\end{abstract}

Key word index: Ozone, vehicle emissions, emission models, speciated organics.

\section{INTRODUCTION}

The relatively high levels of ambient ozone in Vancouver have led to the need to better understand the sources of the ozone-forming precursors, $\mathrm{NO}_{x}$ and nonmethane hydrocarbons (NMHC), in the Lower Fraser Valley (LFV). Emissions inventories (e.g. U.S. Environmental Protection Agency, 1992) show motor vehicles as a leading source of $\mathbf{N O}_{x}$ and gas-phase hydrocarbons (HC), the main precursors of urban/ regional $\mathrm{O}_{3}$. Similarly, the 1990 Vancouver emission inventory assigns $77.3 \%$ of the total $\mathrm{NO}_{x}$ emissions to mobile sources (GVRD, 1994). Motor vehicles are also the main source of $\mathrm{CO}$. However, it was not until the experiment by Ingalls (1989) and Ingalls et al. (1989) in an urban tunnel in Van Nuys, California during the 1987 Southern California Air Quality Study (SCAQS) that attention was drawn to the possibility that motor vehicle emissions of $\mathrm{CO}$ and $\mathrm{HC}$ (though not $\mathrm{NO}_{x}$ ) may be underestimated by a factor of 2 or more. The Van Nuys study raised serious questions regarding the predicted importance of mobile sources toward ozone formation, since mobile sources are the largest contributor to $\mathrm{CO}$ and $\mathrm{HC}$ emissions in urban areas (Pierson et al., 1990).

Recently, a number of experiments have been conducted in highway tunnels to measure, in an on-road setting, the emissions from mobile sources, and compare these results with model/inventory predictions in order to understand why the present $\mathrm{O}_{3}$ strategies are not working (Pierson et al., 1996). Concerns raised by these studies prompted Environment Canada to sponsor a tunnel study by the Desert Research Institute (DRI) in Vancouver's Cassiar Tunnel to assess on-road emissions in the LFV during the 1993 Lower Fraser Valley Oxidants Study (LFVOS).

The objectives of this study were:

- To provide a real-world comparison of observed $\mathrm{CO}$, nonmethane hydrocarbons (NMHC), and $\mathrm{NO}_{x}$ against automobile emission models, MOBILE4.1C and MOBILE5C (the "Canadianized" version of the U.S. EPA MOBILE model).

- To provide real-world emission rates of $\mathrm{NO}_{x}$ and speciated gas-phase NMHC as input for calculating the $\mathrm{O}_{3}$-forming potential of automotive emissions.

- To provide a real-world emission rate for $\mathrm{CO}$. 
Table 1. Summary of run times, average speed $\left(\mathrm{km} \mathrm{h}^{-1}\right)$, vehicle counts, and vehicle fraction

\begin{tabular}{rccccrrrrr}
\hline Run \# & Date & Run time & $\begin{array}{c}\text { Avg. } \\
\text { spd. }\end{array}$ & $\begin{array}{c}\text { Total } \\
\text { vehicles }\end{array}$ & LDSI & HDSI & HDD & F-LD & F-HD \\
\hline 1 & $8 / 13 / 93$ & $0200-0300$ & 93.2 & 125 & 111 & 4 & 10 & 0.888 & 0.112 \\
2 & $8 / 13 / 93$ & $0600-0700$ & 95.1 & 1678 & 1532 & 58 & 88 & 0.913 & 0.087 \\
3 & $8 / 13 / 93$ & $1000-1100$ & 91.0 & 1821 & 1607 & 79 & 135 & 0.882 & 0.118 \\
4 & $8 / 13 / 93$ & $1500-1600$ & 91.7 & 2502 & 2354 & 81 & 67 & 0.941 & 0.059 \\
5 & $8 / 14 / 93$ & $0900-1000$ & 93.2 & 1470 & 1356 & 52 & 62 & 0.922 & 0.078 \\
6 & $8 / 15 / 93$ & $0900-1000$ & 92.4 & 948 & 897 & 39 & 12 & 0.946 & 0.054 \\
7 & $8 / 16 / 93$ & $0200-0300$ & 94.6 & 93 & 75 & 4 & 14 & 0.806 & 0.194 \\
8 & $8 / 16 / 93$ & $0600-0700$ & 96.1 & 1622 & 1434 & 86 & 102 & 0.884 & 0.116 \\
9 & $8 / 16 / 93$ & $0800-0900$ & 92.1 & 1859 & 1605 & 121 & 133 & 0.863 & 0.137 \\
10 & $8 / 18 / 93$ & $0200-0300$ & 91.7 & 100 & 90 & 2 & 8 & 0.900 & 0.100 \\
11 & $8 / 18 / 93$ & $0600-0700$ & 96.6 & 1650 & 1471 & 76 & 103 & 0.892 & 0.108 \\
12 & $8 / 18 / 93$ & $0800-0900$ & 91.4 & 2074 & 1837 & 108 & 129 & 0.886 & 0.114 \\
13 & $8 / 18 / 93$ & $1000-1100$ & 89.6 & 1769 & 1546 & 110 & 113 & 0.874 & 0.126 \\
14 & $8 / 18 / 93$ & $1200-1300$ & 89.9 & 1850 & 1638 & 99 & 113 & 0.885 & 0.115 \\
15 & $8 / 18 / 93$ & $1400-1500$ & 90.2 & 1977 & 1800 & 67 & 110 & 0.910 & 0.090 \\
16 & $8 / 18 / 93$ & $1600-1700$ & 89.6 & 2975 & 2866 & 66 & 43 & 0.963 & 0.037 \\
\hline
\end{tabular}

- To evaluate the relative contributions of lightduty (LD) and heavy-duty (HD) vehicle emissions in the LFV.

- To evaluate the relative importance of tailpipe and nontailpipe NMHC from mobile sources (see McLaren et al., 1996).

\section{EXPERIMENTAL METHODS}

\section{Measurement of emissions in tunnels}

The method of measuring mobile source emissions in tunnels has been described in detail by Pierson et al. (1996). Briefly, the mass of any given constituent produced by vehicles in the tunnel is given by

$$
M=\sum_{i}\left(C_{\text {out }} V_{\text {out }}\right)_{l}-\sum_{j}\left(C_{\text {in }} V_{\text {in }}\right)_{j}
$$

where $\left(C_{\text {out }} V_{\text {out }}\right)_{i}$ is the product of concentration $C_{\text {out }}\left(\mu \mathrm{g} \mathrm{m}^{-3}\right)$ and volume of air $V_{\text {out }}\left(\mathrm{m}^{3}\right)$ for each of the $i$ exit channels (exhaust ducts, exit portal), and similarly for $\left(C_{\text {in }} V_{\text {in }}\right)_{\text {. }}$. For the case of the Cassiar Tunnel, there is only one entrance and one exit; thus $i=j=1$.

Concentrations in ppb or ppm were converted to mass concentrations assuming standard temperature and pressure. The total vehicle counts and the vehicle class distributions of those counts were obtained by recording the traffic flow during the sampling period and reviewing video tapes of the runs to obtain both the total vehicle count and the class-specific vehicle counts. Given the total traffic count $N$, and the known length $L n$ of the tunnel, the average emission rate $E M F$ in $g_{\text {veh-mile }}^{-1}$ is given by

$$
\mathrm{EMF}=\frac{M}{N * \operatorname{Ln}} .
$$

For this study, the motor vehicle fleet was divided into three major classes. The light-duty spark ignition, LDSI, heavy-duty spark ignition, HDSI, and heavy-duty diesel, HDD. In order to separate mathematically HD and LD emissions, the HDSI and HDD vehicle classes were combined to form a heavy-duty (HD) class and the LDSI vehicles was termed the light-duty (LD) class.

\section{Tunnel description}

The Cassiar Tunnel is an urban two-bore tunnel, $730 \mathrm{~m}$ in length, with two lanes of traffic per bore. It is situated on the Trans-Canada Highway, Highway 1, in Vancouver, BC. Traffic is generally heavy during the day. Speeds ranged between 89.6 and $96.6 \mathrm{~km} \mathrm{~h}^{-1}$. Hourly traffic counts ranged from approximately 100 vehicles during the early morning hours to almost 3000 vehicles during the afternoon rush hours (see Table 1). The grade within the tunnel varies from $+1.66 \%$ at the south end to $-1.29 \%$ at the north end. The nearest entrance ramps before the tunnel are over $1000 \mathrm{~m}$ to the south and connect with major arteries. Cold-start operation should therefore be minimal in the tunnel.

Ventilation for the tunnel is achieved from the piston effect of the vehicles traversing it and from fans positioned along the ceiling throughout the tunnel. The fans were used only when high levels of $\mathrm{CO}$ were present in the tunnel. They were not activated throughout the course of this study. The surrounding area is primarily residential, with one major urban street located over the middle of the tunnel. Contamination from background sources is eliminated using the emissions calculation methodology outlined in the previous section.

\section{Measurement protocol}

A total of $16 \mathrm{l}-\mathrm{h}$ runs were conducted at various times of the day beginning at $0200 \mathrm{~h}$ on 13 August 1993 and ending at $1700 \mathrm{~h}$ on 18 August 1993. Table 1 lists the dates and time periods for the sampling runs. For all runs, the average model year was 1988.5 for cars and 1989.3 for sport utilities/pickups. Overall, the average model year for the LD vehicle class was 1988.8 .

Sampling sites were set up at the north and south ends of the tunnel. At each location, a metal framework of angle iron was set up to position the sample lines over the edge of the concrete buttress above and to hang below the ventilation fans and into the top of the tunnel. Attached to the angle iron were propeller anemometers lined up parallel to the roadway to measure the total volumetric air flow through the tunnel. There were no walkways within the tunnel on which to locate additional sampling stations which would have reduced the uncertainty in the observed air flows and emissions. (In order to reduce the possible uncertainty in air flow measurements, $\mathrm{SF}_{6}$ should be used in future experiments as a check of the air flow in the tunnel) Power for the samplers was supplied by using $20 \mathrm{~A}$ gasoline generators set back 
Table 2. Total fleet $(H D+L D)$ run observed and MOBILE predicted emission factors and vehicle weighted average emission factors for the 15 valid runs

\begin{tabular}{|c|c|c|c|c|c|c|c|}
\hline \multirow[b]{2}{*}{ Date } & \multirow[b]{2}{*}{ Run } & \multicolumn{3}{|c|}{ Measured emission factors (g veh-mile ${ }^{-}$} & \multicolumn{3}{|c|}{ MOBILE4.1C/MOBILE5C emission factors (g veh-mile ${ }^{-1}$} \\
\hline & & $\mathrm{CO}$ & NMHC & $\mathrm{NO}_{x}$ & $\mathrm{CO}$ & NMHC & $\mathrm{NO}_{x}$ \\
\hline $8 / 13 / 93$ & 1 & 6.40 & 1.82 & 2.88 & $5.68 / 8.96$ & $0.38 / 0.64$ & $2.43 / 3.42$ \\
\hline 8/13/93 & 2 & 12.5 & 0.70 & 4.00 & $8.29 / 14.5$ & $0.50 / 0.91$ & $2.46 / 3.59$ \\
\hline $8 / 13 / 93$ & 3 & 8.98 & 0.58 & 2.70 & $6.19 / 9.25$ & $0.43 / 0.71$ & $2.53 / 3.45$ \\
\hline $8 / 13 / 93$ & 4 & 8.52 & 0.45 & 1.81 & $6.11 / 9.21$ & $0.39 / 0.73$ & $1.52 / 2.51$ \\
\hline $8 / 14 / 93$ & 5 & 6.56 & 0.36 & 1.63 & $7.47 / 10.7$ & $0.44 / 0.73$ & $1.88 / 2.80$ \\
\hline $8 / 15 / 93$ & 6 & 7.16 & 0.37 & 1.54 & $5.89 / 9.89$ & $0.36 / 0.69$ & $1.16 / 2.15$ \\
\hline $8 / 16 / 93$ & 7 & 9.35 & 0.49 & 3.41 & $7.40 / 11.9$ & $0.52 / 0.85$ & $4.59 / 5.65$ \\
\hline $8 / 16 / 93$ & 8 & 11.8 & 0.61 & 3.93 & $9.32 / 15.9$ & $0.54 / 0.99$ & $2.73 / 3.87$ \\
\hline $8 / 16 / 93$ & 9 & 14.3 & 0.85 & 4.06 & $6.36 / 9.92$ & $0.41 / 0.72$ & $2.44 / 3.40$ \\
\hline $8 / 18 / 93$ & 10 & 8.88 & 0.54 & 2.85 & $6.23 / 9.31$ & $0.42 / 0.69$ & $2.58 / 3.51$ \\
\hline $8 / 18 / 93$ & 11 & 11.4 & 0.75 & 3.84 & $10.5 / 18.8$ & $0.60 / 1.11$ & $2.85 / 4.09$ \\
\hline $8 / 18 / 93$ & 12 & 14.1 & 0.77 & 3.85 & $5.68 / 8.80$ & $0.40 / 0.68$ & $2.21 / 3.11$ \\
\hline $8 / 18 / 93$ & 13 & 7.89 & 0.48 & 2.07 & $5.04 / 7.25$ & $0.38 / 0.63$ & $2.14 / 2.96$ \\
\hline $8 / 18 / 93$ & 14 & 6.83 & 0.39 & 1.75 & $6.07 / 8.47$ & $0.44 / 0.73$ & $2.21 / 3.10$ \\
\hline $8 / 18 / 93$ & 15 & 5.62 & 0.33 & 1.36 & $4.46 / 6.75$ & $0.34 / 0.59$ & $1.94 / 2.74$ \\
\hline $8 / 18 / 93$ & 16 & 11.2 & 0.83 & 2.16 & $4.09 / 5.95$ & $0.30 / 0.53$ & $1.02 / 1.79$ \\
\hline \multicolumn{2}{|c|}{ Weighted } & 9.91 & 0.59 & 2.66 & $6.38 / 10.1$ & $0.42 / 0.73$ & $2.05 / 3.00$ \\
\hline
\end{tabular}

${ }^{3}$ Without run \# $1(8 / 13 / 93,0200-0300)$.

approximately $18 \mathrm{~m}$ from the sampling locations, and out of the airflow of the sampling inlets.

One-hour samples were collected using Tedlar bag sam. plers. The bags were analyzed immediately following collection for $\mathrm{CO}$, total hydrocarbon (THC), and $\mathrm{NO}_{x}$ using a TECO model 48 gas filter correlation $\mathrm{CO}$ analyzer, a Baseline Model 15 THC analyzer, and a TECO model 42A chemiluminescence $\mathrm{NO} / \mathrm{NO}_{2} / \mathrm{NO}_{x}$ analyzer. Before reuse, the Tedlar bags were evacuated, filled with zero air, and then reevacuated.

Differences between inlet and outlet THC values were small. The uncertainty present in the THC analysis precluded use of these data and these values are not reported Instead, the sum of the NMHC species $\left(C_{2}-C_{10}\right)$ obtained from canister sampling was used in the calculation of emission factors. Laboratory analysis of the canisters was carried out by Environment Canada at River Road Labs in Ottawa, Ontario (Dann et al., 1994).

\section{RESULTS}

\section{On-road emission factors}

The total fleet (HD + LD) emission factors for each individual run were calculated using the methodology described earlier and are listed in Table 2. Emission factors are dependent on a number of variables, including traffic composition, distribution of emitters (i.e. were there a large fraction of like-emitting vehicles?), speed, temperature, etc. Vehicle class and age distributions do not account for all of the data scatter. The run on 13 August from 0200 to 0300 has an abnormally high NMHC emission factor, $1.82 \mathrm{~g}$ vehmile $^{-1}$, which is more than double the next highest value $\left(0.85 \mathrm{~g}\right.$ veh-mile $^{-1}$ on 18 August 1993,0800 0900). There are a number of possible explanations. The sample may have been contaminated by oper- ator-transferred gasoline used for the power generator, or by direct emission contamination from the on-site power generator. Alternatively, the run may have had an unusually high fraction of high-emitting vehicles. It is difficult to determine which explanation is correct and so this run was treated as an outlier and not used in the determination of the results.

The LD and HD emission rates were calculated by weighted regression (Computing Resource Center, 1992), weighting each run by the total number of vehicles traversing the tunnel during the run. The rationale is that each run is heavily influenced by the total number of vehicles. Over the length of the study, the total number of vehicles per run ranged from 93 to 2975. A few high emitters can cause a low-traffic run to appear to be an outlier even though it may be quite valid.

\section{Comparison with recent tunnel studies}

Using the methodology described by Pierson et al. (1996), separation of the LD and HD contributions to the observed emissions can be achieved. There were a number of limitations in the experiment which precluded accurate separation of the LD and HD emissions components. These were:

- There was insufficient differences between the HDD and HDSI fractions to separate contributions from these vehicle classes.

- The HDD and HDSI fractions were combined. The rationale for this was to eliminate a high bias in the estimated LD from HDSI fraction. HDSI emissions are greater than LDSI emissions and more closely resemble those from the HDD fraction of the fleet. 
Table 3. Light-duty emission factors for CO, NMHC, and $\mathrm{NO}_{x}$, for the Cassiar, Tuscarora, and Fort McHenry tunnels (in g veh-mile ${ }^{-1}$ )

\begin{tabular}{lccc}
\hline & Cassiar & Tuscarora & Fort McHenry \\
\hline CO & $8.23 \pm 2.27$ & $4.89 \pm 0.49$ & $6.35 \pm 0.54$ \\
NMHC & $0.58 \pm 0.16$ & $0.29 \pm 0.06$ & $0.62 \pm 0.10$ \\
NO $_{x}$ & $1.15 \pm 0.73$ & $0.39 \pm 0.26$ & $0.81 \pm 0.09$ \\
\hline
\end{tabular}

- The combined HD fraction varied from 5.3 to $19.4 \%$. The HDD fraction varied from 1.3 to $15.0 \%$, with all but one run in the range of $5.4-13.7 \%$. Extrapolating to $100 \% \mathrm{HD}$ (or HDD) leads to large uncertainties in the HD (or HDD) estimates.

Given the uncertainty in the HD emission factors, only the LD results are listed in Table 3 . These results are compared to two studies performed in the U.S. in 1992 at the Tuscarora Tunnel along the Pennsylvania Turnpike and the Fort McHenry Tunnel located in Baltimore, MD (Pierson et al., 1996).

In reviewing Table 3, it is important to consider the differences among the tunnels. The Tuscarora Tunnel is rural interstate highway tunnel, approximately 1 mile long, with the nearest entrance to the parkway $10 \mathrm{~km}$ from the tunnel. The traffic through the tunnel is operating in a hot stabilized running condition, and there is essentially no grade throughout the length of this tunnel. The highest fractions of HD traffic occurred during the night, with the daytime traffic composed primarily of LD vehicles. The Fort McHenry Tunnel is situated on a major north-south interstate freeway in the middle of the third largest seaport on the east coast of the U.S. It is $2174 \mathrm{~m}$ long, has a grade which ranges from -3.76 to $+3.76 \%$ throughout its length, and has its nearest on-ramps approximately $2200 \mathrm{~m}$ before the tunnel. The tunnel has a large number of HDD trucks traversing the tunnel. There are two bores in each direction, one carrying primarily LD traffic and the other composed of a mixture of $L D$ and HD vehicles. The Cassiar Tunnel is similar to Tuscarora in that it is straight and flat; however, it is located in an urban area and there is little diurnal variation in vehicle fleet composition, which is mostly light-duty.

There are two other major differences between the U.S. tunnels and the Cassiar Tunnel. The first is that the type of fuel used in Canada can be significantly different from fuel used in the U.S.; the second is that the emissions restrictions for U.S. vehicles are stricter than those for Canadian vehicles in model years 1981-1988. The effect of differences in gasoline composition is unknown since the effect of regional differences in gasoline composition on emission factors in both the U.S. and Canada has been largely unexplored (apart from RVP effects). The effect of the differences in emissions control technology is that emission factors in Canada are higher than those in the U.S. for roadways that support a significant frac- tion of vehicles of model years 1981-1988. (Using the same input parameters, the U.S. version of MOBILE predicted approximately $3-10 \%$ lower emissions for the U.S. technology vehicles). These factors should lead to greater emission factors for a Canadian fleet similar in age to a U.S. fleet.

The average model year distributions for all three tunnels are very similar. For Tuscarora, the average model years were 1988.7 for cars, 1990.2 for sport utility vehicles, and 1989.1 for pickups. The overall average model year of LD vehicles was 1989.0. Fort McHenry was similar to Tuscarora; the average model years were 1989.0 for cars, 1990.2 for sport utility vehicles, 1988.5 for pickups, and 1989.0 for the LD vehicle class. These can be compared to the Cassiar values of 1988.5 for cars, 1989.3 for sport utility/pickups, and a light-duty vehicle average of 1988.8 . (Since the Fort McHenry and Tuscarora experiments were performed in 1992 and Cassiar was performed in 1993, the Cassiar fleet was 1 yr older than the fleets in the earlier experiments.)

The LD emission factors for $\mathrm{CO}$ are significantly higher in the Cassiar Tunnel than those in either the Tuscarora or Fort McHenry Tunnels, although the uncertainty of the Cassiar value is large enough to encompass the Fort McHenry values. Both NMHC and $\mathrm{NO}_{x}$ emissions were lowest in Tuscarora and of similar value for Fort McHenry and Cassiar.

As discussed by Gertler et al. (1994), the increased emissions in Fort McHenry as opposed to Tuscarora may be due to the impact of grade on emissions. Cassiar, on the other hand, is fiat and the results should be similar to those observed in Tuscarora. The increased emissions observed in Cassiar are likely to have resulted from three sources: (1) the difference in technology between the U.S. and Canadian fleets, (2) the urban and suspected to be more poorly maintained nature of the Vancouver fleet as opposed to the interstate and likely to be well maintained fleet observed in Tuscarora and Fort McHenry (the conjecture regarding the quality of maintenance has less to do with whether or not the fleets are part of an inspection and maintenance program but rather on the tendency to drive ones better car on long trips), and (3) the fleet is 1 yr older at Cassiar.

\section{MOBILEA.1C AND MOBILESC COMPARISON}

\section{Modeling methodology}

Mobile emission factors were calculated using MOBILE4.1C (Terrillon, 1991) and MOBILE5C (Philpott, 1993), the Canadian versions of the EPAdeveloped on-road mobile emission factor models. Emission factors were calculated for the eight vehicle types in the models for each of the 16 runs. Average hourly conditions (temperature, speed, etc.) were used and on-road emission factors were calculated for $\mathrm{CO}$, NMHC, $\mathrm{NO}_{x}$ by taking a vehicle count weighted average of the emission factors for each vehicle type. 
Table 4. Observed and model-predicted emission factors for $\mathrm{CO}, \mathrm{NMHC}$, and $\mathrm{NO}_{x}$

\begin{tabular}{lrcc}
\hline & CO & NMHC $^{\mathbf{2}}$ & NO $_{x}$ \\
\hline Observed & 9.91 & 0.59 & 2.66 \\
MOBILE4.1C & 6.38 & 0.42 & 2.05 \\
MOBILE5C & 10.09 & 0.73 & 3.00
\end{tabular}

Model performance (comparison to measurements)

\begin{tabular}{lrrr}
\hline MOBILE4.1C & $-36 \%$ & $-29 \%$ & $-23 \%$ \\
MOBILE5C & $+2 \%$ & $+24 \%$ & $+13 \%$
\end{tabular}

${ }^{a}$ NMHC includes exhaust and running loss emissions for model predictions.

Speed measurements in the tunnel were supplied by the Ministry of Transportation and Highways Contractor, Capillano Highway Services Company, and averaged between 89.2 and $96.6 \mathrm{~km} \mathrm{~h}^{-1}$ (posted speed was $70 \mathrm{~km} \mathrm{~h}^{-1}$ ). Temperatures were taken from nearby air-quality monitoring station readings and were relatively cool, ranging from 13 to $23^{\circ} \mathrm{C}\left(55^{\circ}\right.$ to $\left.73^{\circ} \mathrm{F}\right)$ during the 16 runs. The Reid Vapor Pressure (RVP) of the gasoline was assumed to be equivalent to that sold in the Lower Fraser Valley. An average RVP, 8.6 psi, was calculated from data collected during August as part of the Pacific 93 field study (Steyn et al., 1996). A grade split of $77 \%$ regular unleaded $/ 10 \%$ mid grade unleaded $/ 13 \%$ premium unleaded was used to weight the RVP data. Model year distributions were obtained from video tapes and diesel fractions specific to the Vancouver region were calculated from vehicle registration data provided by the Air Care Administration, the local vehicle inspection and maintenance (I/M) program in Vancouver.

\section{Comparison of observations emissions and model predictions}

The calculated emission factors along with the observed emissions are shown in Table 4 for MOBILE4.1C and MOBILE5C. Emission factors are given for $\mathrm{CO}, \mathrm{NMHC}$ (composed of exhaust + running loss estimates from the model), and $\mathrm{NO}_{x}$. Runweighted model performance results are presented in Table 4. MOBILE5C overpredicts the observed value of $\mathrm{CO}$ by $\sim 2 \%$, NMHC by $24 \%$, and $\mathrm{NO}_{x}$ by $13 \%$. This is compared to MOBILE4.1C, which underpredicts the observed values by approximately 36,29 , and $23 \%$ for $\mathrm{CO}, \mathrm{NMHC}$, and $\mathrm{NO}_{x}$, respectively.

The run-weighted $\mathrm{CO} / \mathrm{NO}_{x}$ and $\mathrm{NMHC} / \mathrm{NO}_{x}$ ratios for the 15 valid runs are given in Table 5. (The use of ratios reduces the uncertainty in the results since they are independent of the air flow in the tunnel.) The observed $\mathrm{CO} / \mathrm{NO}_{x}$ ratio of $3.55 \pm 1.67$ has a large enough uncertainty to easily encompass the MOBILE4.1C and SC values of $2.90 \pm 1.31$ and $3.23 \pm 1.41$, respectively. Here, the models are predicting the emissions ratios seen at the Cassiar Tunnel, with the discrepancies in the ratios possibly attributed to the uncertainties present in the model input, the
Table 5. $\mathrm{CO} / \mathrm{NO}_{x}$ and $\mathrm{NMHC} / \mathrm{NO}_{x}$ mass ratios from the Cassiar Tunnel

\begin{tabular}{lll}
\hline & $\mathrm{CO} / \mathrm{NO}_{x}$ & NMHC/NO $_{x}$ \\
\hline Observed & $3.55 \pm 1.67$ & $0.207 \pm 0.010$ \\
MOBILE4.1C & $2.89 \pm 1.71$ & $0.217 \pm 0.007$ \\
MOBILE5C & $3.23 \pm 1.98$ & $0.244 \pm 0.007$ \\
\hline
\end{tabular}

composition of vehicles for each run, or in the sampling uncertainty.

The observed NMHC/NO $/ \mathrm{Natios}$ are also relatively close to the predicted values $(0.217 \pm 0.086$ and $0.244 \pm 0.083$, for MOBILE4.1C and SC and $0.207 \pm 0.102$ observed). MOBILE5C overpredicts the ratio of the observed values by approximately $18 \%$, but lies within the experimental uncertainty of the observed values, while MOBILE4.1C underpredicts the observed value, and also lies within the uncertainty range.

While MOBILE5C generally overpredicts and MOBILE4.1C generally underpredicts the emissions, they both appear to predict the $\mathrm{CO} / \mathrm{NO}_{x}$ and NMHC/NO ${ }_{x}$ ratios fairly well. Thus, even though the absolute values of the model predictions are off, with MOBILE4.1C regularly underpredicting and MOBILE5C regularly overpredicting, the ratios are in agreement.

Further improvements in the MOBILE models need to address the effects of commuting driving conditions, i.e. aggressive driving, and the possibility of the models underestimating the contributions of new vehicles, etc. These effects are seen in run \#16, which has the greatest speed variability and youngest vehicle fleet, in addition to the largest differences between the MOBILE model predictions and the observed emission factors.

\section{SUMMARY AND CONCLUSIONS}

In order to understand the factors leading to high ozone in the Vancouver region, a limited study was undertaken in the Cassiar Tunnel on the Trans-Canada Highway to measure the on-road contribution to the ozone-forming precursors along with $\mathrm{CO}$. The observed on-road emission factors were compared to MOBILE5C and MOBILE4.1C (the Canadian versions of the US Environmental Protection Agency's MOBILE models) to assess uncertainty in the predicted mobile source contributions to the $V$ ancouver emissions inventory.

A total of $161-\mathrm{h}$ runs were made at the Cassiar Tunnel beginning on 13 August 1993 and ending on 18 August 1993. The timing of the individual runs was made to encompass different traffic volumes, driving conditions, and times of day. During the 16 runs, a total of 24,513 vehicles traversed the tunnel, with approximately $91 \%$ light-duty vehicles, $4 \%$ heavy-duty 
spark ignition vehicles, and $5 \%$ heavy-duty diesel vehicles.

Taking into account traffic volume and weighting the results, MOBILE5C overpredicted the observed value of $\mathrm{CO}$ by $\sim 2 \%$, NMHC by $24 \%$, and $\mathrm{NO}_{x}$ by $13 \%$ while MOBILE4.1C underpredicted the observed values by 36,29 and 23 for CO, NMHC, and $\mathrm{NO}_{x}$, respectively. It should be noted, however, that the tunnel measurements represent a best case scenario. The vehicles were operating under hot-stabilized conditions and at relatively constant speed. Under normal driving conditions with more variable speed and acceleration but with the average speed the same as for those vehicles traversing the tunnel, emissions would be expected to increase and the models are likely to underpredict the emissions.

The comparison of the MOBILE models to the observed emission factors demonstrates the limitations of the models. While there is run-to-run variability, MOBILE5C generally overpredicts the emissions of $\mathrm{CO}, \mathrm{NMHC}$, and $\mathrm{NO}_{x}$ while MOBILE4.1C regularly underpredicts the by-run emission factors. In spite of this, the ratios of $\mathrm{CO} / \mathrm{NO}_{x}$ and $\mathrm{NMHC} / \mathrm{NO}_{x}$ are in good agreement.

Acknowledgements-We would like to acknowledge the support of Environment Canada under contract number K2034-3-1034. We would also like to thank Fred Prystarz of the Greater Vancouver Regional District for his technical assistance in the sampling and for the on-site bag analysis at the Cassiar Tunnel and Daniel Wang of Environment Canada for the speciated NMHC results for this study. We also acknowledge the fuel analyses provided by ESSO Laboratories in Sarnia, Ontario, and the assistance of the Canadian Petroleum Products Institute (CPPI) which helped coordinate the gasoline sampling program in Canada. We also thank Dave Gourley of British Columbia's Air Care Program who provided data to support the MOBILE modeling.

\section{REFERENCES}

Computing Resource Center (1992) Stata Reference Manual: Release 3, Vol. 1, 5th edn, pp. 315-320. Computing Re- source Center, 1640 Fifth Street, Santa Monica, California.

Dann T., Wang D., Steenkamer A., Halman R. and Lister M. (1994) Volatile organic compound measurements in the Greater Vancouver Regional District 1989-1992. Report No. PMD 94-1, Pollution Measurement Division, Environment Canada, Ottawa.

Gertler A. W., Pierson W. R., Wittorff D. N. and Robinson N. F. (1994) Where do tunnel studies fit in for emissions inventory development? Proc. $A \& W M A$ Conference on Emission Inventory: Applications and Improvement, Air \& Waste Management, Pittsburgh, PA.

Ingalls M. N. (1989) On-road vehicle emission factors from measurements in a Los Angeles Area Tunnel. Paper 89. 137.3, Air \& Waste Management Association 82nd National Meeting, Anaheim, CA, June 1989.

Ingalls M. N., Smith L. R. and Kirksey R. E. (1989) Measurements of on-road vehicle emission factors in the California South Coast Air Basin--Vol. I: regulated emissions. Report No. SwRI-1604 from Southwest Research Institute to the Coordinating Research Council, Atlanta, GA, June 1989. NTIS Document PB89220925.

McLaren R., Wittorff D. N., Gertler A. W., Belzer W. and Dann T. (1996) Determination of evaporative hydrocarbon emissions from on-road vehicles in the Cassiar tunnel study. Envir. Sci. Technol. 30, 3001-3009.

Philpott S. (1993) MOBILESC User's Guide. Transportation Systems Division, Environment Canada.

Pierson W. R., Gertler A. W., Robinson N. F. and Bradow R. L. (1990) Comparison of the SCAQS tunnel study with other on-road emission data. J. Air Waste Man. Ass. 40, 1495-1504.

Pierson W. R., Gertler A. W., Robinson N. F., Sagebiel J. C., Zielinska B., Bishop G. A., Stedman D. H., Zweidinger R. B. and Ray W. D. (1996) Real-world automotive emissions-summary of studies in the Fort McHenry and Tuscarora Mountain Tunnels. Atmospheric Environment 30, 2233-2256.

Steyn D. G., Bottenheim J. W. and Thomson R. B. (1996) Overview of tropospheric ozone in the Lower Fraser Valley, and the PACIFIC 1993 Field Study. Atmospheric Environment (this issue).

Terrillon F. (1991) Adapting MOBILE4.1 to model the Canadian Motor Vehicle Fleet. Transportation Systems Division, Environment Canada.

U.S. Environmental Protection Agency (1992) National air Pollutant Estimates, 1900-1991. EPA Document EPA454/R-92-013, Office of Air Quality Planning and Standards, Research Triangle Park, North Carolina, October 1992. NTIS Document PB93-157808. 